\title{
Astronomi Aletleri Tarihi: Usturlap ve Rubu Tahtası
}

\author{
S. Ertan Tağman ${ }^{1^{*}}$ \\ ${ }^{1}$ Burdur Mehmet Akif Ersoy Üniversitesi, Fen-Edebiyat Fakültesi, Felsefe Bölümü, Burdur, Türkiye \\ ORCID: S.E. Tağman (0000-0002-4277-6726.)
}

\begin{abstract}
Özet
Bilim tarihi çalışmaları "klasik" eserler üzerinden bir anlam kurma çabası olarak tanımlanabilir. Latince Classius'tan türemiş, "en yüksek sınıfa mensup" anlamına gelen bu ve giderek tek başına mükemmellik ifade eden bu sözcük, egemen sınıfların üstünlüğünün bir parçası haline gelmiştir. Geçmişin seçkin ve gösterişli yapıtlarını ifade etmek ve daha çok geçmişe duyulan bir hayranlığı dile getirmek için kullanılan bu sözcüğün içeriği bugünkü imkânlara sahip olmayan ataların nasıl olup da muazzam bilgilere ulaştığına dair merakı barındırmaktadır. Bu bilgilerden şüphesiz en dikkat çekici olan astronomidir. Bu çalışmanın amacı, gökyüzünün bu ilgi çekici ahenginde düzenlilik arayan insanların, bu düzenliliği saptamak için kullandıkları astronomi aletleri hakkında kısa bir bilgilendirme yapmak ve bu aletlerin astronominin gelişimine katkısını belirlemektir. Bunun için özellikle usturlap ve usturlapla aynı ilkelere göre oluşturulan ve usturlabın $1 / 4$ biçiminde olan rub'u tahtası gibi aletler hakkında bilgi verilecek ve astronomi tarihi içerisindeki yeri gösterilmeye çalışılacaktır. Bu aletler hakkındaki bilgilerimiz astronomi anlayışımıza önemli katkılar sunmaktadır.
\end{abstract}

Anahtar Kelimeler: Astronomi, Usturlap, Rub'u Tahtası, Astronomi Aletleri

\section{History of Astronomical Instruments: Astrolabe and Sinecal Quadran}

\begin{abstract}
Studies in the history of science can be defined as an effort to establish a meaning through "classical" works. This term is derived from the Latin term Classius means "belonging to the highest class". This term with increasingly solitary perfection becomes a concept that is part of the supremacy of the dominant classes. The content of this concept, which is used to express the distinguished and ostentatious works of the past and to express an admiration for the past, includes the curiosity about how the ancestors, who did not have today's opportunities, reached spectacular knowledge. Undoubtedly, the most striking one of these knowledge is astronomy. Accordingly, the aim of this study is to give a brief information about the astronomical instruments used by people who seek regularity in this interesting harmony of the sky, to determine this regularity and to determine the contribution of these instruments to the development of astronomy. For this purpose, information will be given about tools such as the astrolabe and the quadrant sinecal which is created according to the same principles as the astrolabe and in the form of $1 / 4$ of the astrolabe, and the paper will be tried to show its place in the history of astronomy. We hope that our information of these instruments makes important contributions to our understanding of astronomy.
\end{abstract}

Keywords: Astronomy, Astrolabe, Sinecal Quadrant, Astronomical Instruments

\section{GíRiş}

Bilim; sistemli ve tutarlı bir bilgi kütlesi olarak tanımlandığında, bilimsel çalışma da birikmiş ve sistemleşmiş bilgi ve açıklamalar yardımı ile olguların ve olgular arasındaki ilişkilerin araştırılması olarak kabul edilebilir. Bilimsel bilgi de olgu ve olayların bilgisinden başka olgular arasındaki ilişkilerin bilgisidir. $\mathrm{Bu}$ ilişkiler de rastgele, düzensiz olmaktan öte belirli bir düzenliliğe sahiptir. İnsanın "homo sapiens olarak ortaya çıkmasından itibaren kendi varlığını devam ettirebilmesinin en önemli önkoşulu doğada var olan düzenlilikleri tanıma zorunluluğu" (Pearce Williams, 2018: s. 2) olmuştur. Bu

\footnotetext{
*Yazışma Adresi / Address for Correspondence:

S.E. Tağman, Email: setagman@mehmetakif.edu.tr

Geliş Tarihi / Received Date: 14.07.2021

Kabul Tarihi / Accepted Date: 18.09.2021

Doi: 10.32329/uad.971693
}

tanıma zorunluluğu insana özgü bir entelektüel faaliyet ve muhakeme yetisi olarak deneyimlerin birikimine ve bu deneyimlerin karşılaştırılmasına, sınıflandırılmasına, düzenlenmesine ve isimlendirilmesine dayanmaktadır. Böyle bir çaba insanda mevcut evrene hâkim görünen neden-sonuç fikrini doğurmaktadır. Neden-sonuç fikri, olayların gidişatı hakkında bir tahminde bulunma veya görünemeyenler hakkında öngörü ve varsayımlar üretme şeklinde özetlenebilecek bir hareket tarzının seçiminde insana bir rehber olmaktadır. "Neden-sonuç ilkesini rehber edinme olarak özetlenen hareket tarzı insanlığın gelişimindeki en önemli etken" (George Forbes, 1909, s. 3) olarak görülmektedir. Bu neden-sonuç fikri doğanın hiçbir alanında astronomide olduğu kadar belirgin olmamıştır.

Antik Çağ'da göksel kehanet de (astroloji) dahil olmak üzere, astronominin en eski bilim olduğuna inanılıyordu (N. Swerdlow, 1999). Her ne kadar bunun altında yatan 
sebep dini bir yorumla Seth'in torunlarının geometri ve astronomi bilgisini öğrenip bunu daha sonra Keldaniler ve Mısır yoluyla Greklerin öğrenmiş ve sonraki nesillere aktarmış olması gibi görünse de, gerçekte gökyüzündeki muazzam olaylar insanlığın kaderini doğrudan etkilemiştir. Mezopotamya'daki antik uygarlıklarda, tanrıların gelecekte meydana gelecek olayları insanlara gösterdiklerine inanılıyordu. Bu gösterim "işaretler" ile yapılıyordu ve bu işaretlere Sümerce (g)iskim ve Akad$\mathrm{ca}$ ittu deniliyordu. Bu işaretler kurban edilen hayvanların iç organlarında, suya damlatılan yağ damlacı̆̆ının yayılımında ve gökyüzünde sıra dışı birtakım olaylarda görülüyordu (H. Hunger \& D. Pingree, 1999). Bu bağlamda sadece insanlığın ilerlemesini göstermesi için araçsal olarak kullanılmadıkça kutsal metinlere dayanan kehanet içeren astrolojik ifadelerin ciddiye alınmaması gerektiği de bilim tarihçileri tarafından ileri sürülmüştür (G. Sarton, 1950, s. 374, akt. A. Şen). Diğer taraftan astronomi tarihçisi Otto Neugebauer bu tarz metinleri ciddiye almanın, o dönemin gündelik hayatı, batıl inançları, dinleri, astronomi yöntemleri ve kozmogonik fikirleri hakkında bir anlayıș elde etmemize katkıda bulunacağını ileri sürer (O. Neugebauer, 1951: s. 111, akt. A. Şen). Bilim tarihçileri astrolojik kaygıların ve çalışmaların, yeni astronomi kuramlarının ve araçlarının gelişimi üzerindeki etkilerini incelemeye devam etmektedir. Özellikle modern astronominin doğuşunda önemli isimler olarak karşımıza çıan Kopernik, Kepler, Brahe ve Galilei gibi bilim insanlarının astrolojik kaygıları önemli çalışma konuları olarak karşımıza çıkmaktadır. Metinlere dayanan mevcut görüş, Yunanca kullanımda anlamların pratik olarak ayırt edilemez olduğu yönündedir; "her ikisi de söz konusu iki bilime uygulanabilir" (S. Pines, 1964: s.343). Semantik açıdan, astronomi ve astroloji terimlerinin çok karmaşık bir tarihi vardır. Yunanca metinlerdeki kullanımda, anlamların pratik olarak ayırt edilemez olduğu ileri sürülmektedir; aynı anlam her iki alana da uygulanabilir. Cicero'nun (MÖ 43) Da orotare, Tuvanalı Apollonius'un (MÖ 100 - 15) De haris dieu et noctis, Proclus'un (MS 412) Timaeus Commentary, eserlerinde iki terimden bahsedilir. Bazı tarihçilere göre Sevillalı İsidore (ö. MS 636), iki terim arasındaki ayrışmayı modern anlamda ilk kez dile getiren kişidir:

"Astronomi ve Astroloji arasinda farklilıklar vardir. Çünkü Astronomi gökyüzünün dönüşünü, ortaya çıkışını, yıldızların yörüngelerini ve hareketlerini içermektedir, ya da bu nedenlerle böyle adlandırllmaktadır. Astroloji ise kısmen doğal kısmen doğaüstüdür. Güneşin ve Ay'ın dönüşlerini ya da yıldızların uzaklıklarının belirli duraklarını tanımladiğı zaman doğayla ilgilidir. Yıldızlarda gözlem yapıp gökyüzünün on iki işaretinin her birini ruhun ya da bedenin uzuvlariyla düzenleyen ve ylldızların yönleriyle insanların doğumlarına ve karakterlerine ilișkin kehanette bulunmaya cüret eden matematikçilerin takip ettiği șey doğaüstüdür" (S. Pines, 1964, s.343, içinde; Sevillall İsidore, Etymologiae Bölüm III, XXVII)

Orta Çağ'da ise Victorlu Hugh'un (ö. 1141) Eruditio didascalica eserinde yer alan astroloji ve astronominin tanımları, büyük ölçüde yukarıda alıntılanan Isidore'un pasajına ve aynı bağlamdaki diğer ifadelerine benzemektedir. Michael Glycas, (ö. 1156) eserinde bu iki terimi şu şekilde ifade etmiştir:

"Astronomi, tüm göksel (cisimlerin) konumunu, hareketini ve ayrica düzenli bir araya gelmesini ve ayrılmasını öğrettiği için azizlere bile izin verilmiş bir bilgidir. Eski bir hikâyede duyduğumuz gibi, sorumluluğu yıldızlar olan melek, (yani) Uriel, Seth ve Henoch'a indi ve bunun üzerine onlara mevsimlerin devinimlerini ve ylldızların işaretlerini ögretti. Astroloji, ise bunlardan (șeylerden) türeyen geleceği bildiren tahmin/öngörüdür... Bilgelerimize dahi hiçbir zaman bunun için izin verilmemiştir, çünkü oldukça basit olanları çok fazla saptırır ve dikkatlerini doğuma ve kadere yöneltmeye zorlar." (S. Pines, 1964, s.343 içinde; M. Glycas, Catalogus codicum astrologorum Graecorum)

İster astrolojik kaygılarla olsun ister sivil ve dini yaşamanın düzenlenmesi için etkili bir takvime ihtiyaç duyulması gibi pratik amaçlar için olsun, Güneş'in, Ay'ın ve yıldızların gökteki konumları, tarih öncesi insanı için çok önemliydi. Güneş ve Ay periyodik olarak hareketlerini tekrarlamakta, gece ve gündüz insan varoluşunun temel ritmini sağlamaktadır. Mevsimlerin bilinmesi, insanların binlerce yıldır hayatta kalabilmek için bağımlı olduğu hayvanların göç zamanının ve tarımın icadıyla ekim için uygun zamanın belirlenmesi açısından önemlidir. Gökyüzü, düzen ile beklenmedik olayların iç içe bulunduğu, sürekli değişen bir gösteri gibidir (Ronan, 2003). Gökyüzünde, gezegenlerin dışında, en az onlar kadar ilgi çeken; yeryüzüne düşer gibi görünen göktaşları, parlak alevli kuyruklu yıldızlar, rengarenk gökkuşağı, Güneş ve Ay'in çevresinde oluşan haleler gibi fenomenler dikkat çekmektedir. İnsanlar için bu değişkenlik gösteren ve düzensiz görünen olguların hepsi cezbedici olmaktadır.

Bununla birlikte, salt düzenliliklerin tanınması, bilimin tam anlamını vermeyebilir. Düzenlilikler basitçe insan zihninin yapıları olabilir. İnsanlar doğaları gereği doğrudan genelleme yapmaya ve bir sonuca varmaya meyillidir. Zihin kaosa tahammül edemez, bu yüzden olgusal bir karşılığı olmadığında bile zihin düzenlilikler inşa eder. Örneğin, Orta Çağ’'n astronomi “yasalarından” biri, kuyruklu yıldızların ortaya çıkmasının büyük bir karışıklık habercisi olduğuna ilişkindi! (İngiltere'deki Norman istilasının 1066 kuyruklu yıldızını takip etmesi ya da İstanbul Rasathanesi'nin bir kuyruklu yıldız gözleminden sonra veba salgını bahane edilerek yıkılması). Gerçekten de gökyüzü, her çağda insanlığın hayal gücünü ve evren görüşünü etkilemiştir. 


\section{ISLAM DÜNYASI'NDA ASTRONOMI ALETLERI}

Astronomi kadim milletlerden bugüne kadar insanoğlunun en fazla üzerinde düşündüğü ve uğraştığı bir alan olmuştur. Bunun iki nedeni vardır: (1) gökyüzü ve yeryüzü arasında var olduğuna inanılan gizemli bir ilişki ve (2) insanoğlunun zamanı, gökyüzüne bakarak tanımlama ihtiyacı. Zaman kavramı antik dönemlerden itibaren insanın dikkatini çekmiştir. Bu kavramın sırrını öğrenme arzusu ve onu iyi kullanma bilinci, sonsuzca yaşama emeli ile birleşince ortaya uygarlığın ilk kıvılcımları çıkmıştır. Gece ile gündüzün sürekli birbirini takip etmesi, aynı şekilde Ay’ın düzenli olarak aynı safhalardan geçmesi, insanların zihninde ilk zaman kavramını yaratmıştır. Antik dönemlerde insanlar gök cisimlerini önce korkarak izlemişler, onların periyodik hareketlerine çeşitli anlamlar yüklemeye çalışmışlardır. Bu korkularını çeşitli gök cisimlerine tapacak kadar ileri götürenler olmuştur. Daha sonra bu hareketlerin belirli bir düzen dâhilinde olduğunu anladıkça, zamanı bir belirleme aracı olarak kullanmaya başlamışlardır. İster dini-mitolojik, ister ekonomik veya bilimsel nedenlerle olsun, bütün uygarlıklarda mevsimlerden aylara, aylardan haftalara ve günlere doğru aşama aşama zaman konusunda bir bilinçlenmenin olduğu görülmektedir. Amaç ne olursa olsun bu bilinçlenme gökyüzü ile ilgili daha kesin ve net bilgilere ulaşmak için birtakım araçları zorunlu kılmıştır. İslam Dünyası'nda da özellikle ibadet vakitlerinin belirlenmesi, kıble yönünün tayini, bunun dışında seferler için uğurlu saatlerin belirlenmesi ve diğer askeri ve siyasi amaçlar için astronomi önemli bir bilim olarak görülmüştür.

Arapça 'ilm el-hey'e veya 'ilm el-felek diye anılan astronomi, matematiksel bilimler (el-'ulūm er-riyāziyye) arasında yer alır ve 'ilm ahkām en-nucūm veya şınāat ahkām en-nucūm (yıldızlardan hüküm çıkarma bilimi veya sanatı) diye anılan astrolojiden ayırt edilmektedir (F. Sezgin, 2008). Bu işle uğraşanlara da müneccim ismi verilerek, hem astrolog hem de astronomlar bu gruba dahil edilmiştir. (S. Aydüz, 1995). İslâm'ın ilk devirlerinden beri astronomi sahasında yapılan çalışmalar, zamanla ilerlemiş, daha önceki medeniyetlerin çalışmaları da ilave edilerek özellikle astronomi gözlemleri ile gezegen teorileri konularında büyük başarılar elde edilmiştir. Özellikle Semerkant ve Meraga rasathanelerinde astronomi bilimi zirveye ulaşmıştır. Bunlardan Uluğ Bey'in kurduğu Semerkant gözlemevinin, Osmanlı astronomisi üzerinde büyük etkisi vardır. Osmanlılarda 1800 yılına kadar bütün astronomik ve astrolojik hesaplar Uluğ Bey tarafından hazırlanan Zîc'e göre yapılmıştır (S. Aydüz, 2000). Kullanılan aletler de her dönem üstüne katılarak geliştirilmiştir.

Bununla beraber 8. ve 19. yüzyıl İslam astronomi aletleri hakkındaki bilgiler temelde 2 kaynağa dayanmaktadır; (1) Dünya'da farklı coğrafyalarda yer alan müze ve özel koleksiyonlarda yer alan aletler, (2) Aletlerin yapımı ve kullanımı hakkında kütüphanelerde yer alan yazmalar. İslam dünyasındaki astronomi aletlerinden günümüze 200'e yakın küre, yüzlerce usturlap, düzinelerce Rubu aleti ve tahtası, Güneş saati, bulunmaktadır. Bunların çoğu 8.-12. yüzyıllar arasına aittir. Takiyüddin'ün İstanbul Gözlemevine ait illüstrasyonları bu aletler hakkında önemli veriler sağlamaktadır. İslam astronomi aletleri temel olarak iki kategoride değerlendirilir: Gözlemsel aletler ve gözlemsel-olmayan aletler. İslam astronomlarının kullandığı aletler, genel olarak Batlamyus'un Almajest ve Tetrabiblos adlı eserlerinde anlattığ 1 aletlere yakın biçimde kullanılmıştır. Kullanılan en temel aletler: Halkalı Küre, Paralaks Cetveli, Duvar Kadranı olarak sayılabilir. Halkalı Küre (zät el-halak), Yer'i temsil eden merkezdeki küre etrafında Zodyak burçlarının temsil edildiği halkalar bulunan bir alettir. Kullanıcının enlemine göre ayarlandıktan sonra, yılın herhangi bir gününde gün doğumu saati gibi küresel astronomi sorunlarını çözebilir. Halkalı küre (armillary sphere) gökyüzündeki nesnelerin bir modelidir. Genelde küresel usturlap ile karıştırılmıştır. Oysa küresel usturlap İslam astronomisine ait bir buluştur. Paralaks Cetveli (İki Delikli Alet - el-āle zāt es-sukbeteyn) gökcisimlerin yüksekliğini ve özellikle de Ay'ın zenit ve paralaksını belirlemek için kullanılmıştır. İstanbul Rasathanesi'nde batı ve doğuya döndürülebilir cetvel, sadece meridyendeki Ay paralaksının ölçümüne değil, aynı zamanda bunun da ötesinde uzun bacaklarıyla gök cisimleri yüksekliğinin olabildiğince doğru ölçümüne yaramaktaydı. Rubu Tahtası ve Duvar Kadranı bir dairenin dörtte biri şeklindedir ve rasathane gözlem aracı libne (Duvar Kadranı) ve pratik amaçlarla kullanılan rubû tahtası olarak ikiye ayrılmaktadır. Genel olarak Güneş'in ve diğer gökcisimlerinin yüksekliğine dayanan hesaplamalar yapmak için kullanılmıştır. Bunun dışında kuyuların derinliğini, kulelerin ve dağların yüksekliğini ve derelerin genişliğini ölçmek için de kullanılmıştır. Rubu Tahtasına ilişkin en eski kayıt David King'e (King: 2002), göre Harezmi tarafından Mefâtihu'l-ulûm isimli eserinin altıncı faslının "fî âlâti’l-müneccimât” başlıklı kısmında yer almaktadır.

$\mathrm{Bu}$ aletler dışında İslam rasathanelerinde kullanılan aletler; es-Siczīnin "Planetaryumu", Abdurrahmān eş Şūfī'nin "Gök-Küresi”, Mü'eyyededīn el-'Urdīnnin "Çift Kadranlı Alet” (el-āle zāt er-rub‘ayn). "Çift Bacaklı Alet” (el-āle zāt eş-şubeteyn), "Sinüslü ve Azimutlu Araç” (el-āle zāt el-ceyb ve-s-semt), "Sinüs Ölçümü İçin Dikey Ölçekli Alet" (el-āle zāt el-cuyūb ve-s-sehm), "Mükemmel Alet" (el-āle el-kāmile) sayılabilir.

\section{USTURLAP VE RUB'U TAHTASI ADLI ALETIN KULLANIMI, PARÇALARI, TARIHI VE ÍLKELERI}

İlk kez İslam dünyasında kullanılmaya başlanan Rubu Tahtası, Güneş'in ufuk yüksekliği ölçülerek, hem namaz ve oruç vakitlerinin doğru olarak saptanabildiği hem de açıların trigonometrik fonksiyonları çözülebildiği bir alettir. Bu araçla ayrıca çeşitli aritmetik işlemler de yapı- 
labilir. Bir yüzünde trigonometrik fonksiyonları kâğıt kalem kullanmaksızın hesaplamaya yarayan sinüs çizelgesi vardır ve bu yüze rub'u'l-müceyyeb ya da rub'u'd-düstûr denir. Rub'u'l-müceyyeb, iki kenara paralel olarak bir ya da iki derecelik aralıklarla çizilen ve yarıçapı 60 derecelik ölçeklere bölen bir sinüs çizelgesi ile yay üzerine çizilen 90 derecelik bir ölçekten ibarettir. Bir kullanım kılavuzu yardımıyla sinüs, kosinüs ve kotanjant gibi değerlerin birbirine dönüştürülmesi ya da kıblenin tespiti gibi trigonometrik problemleri kolaylıkla çözmeye yarar. Hesap kolaylığını artırmak için İslâm coğrafyasında müceyyebin birçok çeşidi geliştirilmiştir. (T. Arslan, 2016) Rubu tahtasının temel ilkeleri usturlap aldı alete göre yapılmiştır.

Usturlap, gök cisimlerinin özellikle de Güneş'in ve yıldızların konumlarının belirlenmesi ve zamanın ölçülmesi ile ilgili problemlerin çözümünde kullanılan astronomik bir alettir. Etimolojik olarak Yunancada "yıldız" anlamına gelen Aster ve "almak, ölçmek, yakalamak, tutmak, anlamak ve kavramak” gibi anlamlara gelen Lambanein kökünden gelmektedir. Bu bağlamda usturlap için "yıldızları anlamak için kullanılan bir alet" biçiminde ortak bir tanım yapılabilir. Daha açık ifade etmek gerekirse "gökyüzündeki yıldızları ve diğer nesneleri tespit eden, Güneş'in veya bir yıldızın konumundan yararlanarak zamanı belirleyen alet" biçiminde de tanım yapılabilir. Günümüz diliyle ifade edecek olursak da usturlap "Orta Çağ bilgisayarı" ya da "Orta Çağ saati” anlamlarında da kullanılabilir. Zamanı ölçmek gibi en temel özelliğinin yanı sıra usturlap aynı zamanda gökyüzünün bir haritası ve astronomik problemleri çözen taşınabilir bir alettir. (E. Tağman, 2007, s. 22) Usturlabın ünü kolay taşınması, sezgisel ve esnek olmasından kaynaklanmaktadır.

Usturlabın amacı, kullanıcısına bir yere özgü verilen zamanda ve yerde Güneş'in ve belli yıldızların konumunu göstermektir. Bu gösterme işlemi, usturlabın ön yüzüne gökyüzünün resminin çizilmesi ve yerlerinin kolayca bulunması için gök cisimlerinin konumlarının işaretlenmesi ile yapılır. Birçok astronomi problemi, usturlabın ön yüzü kullanılarak çözülür. Usturlabın ön yüzü sabit parça ve bir eksen üzerinde dönen parça olmak üzere iki tip parçadan oluşur. Sabit parça üzerinde, belli bir enlemde gökyüzünün görüntüsü ve zaman cetvellerini yer alırken, dönen parçalar gökyüzünün günlük dolanımını taklit eder. Usturlap kullanırken belli bir zamanı ve tarihi gösteren parçaların ayarlanması gerekir. İlk oluşturulma aşamasında, gökyüzünün çoğu (görünen ve görünmeyen) aletin yüzünde tasvir edilmelidir. (E. Tağman, 2007)

Usturlap birçok astronomi probleminin görsel yoldan çözülmesine imkân verir. Usturlap hem gözlem hem hesaplama yapmak için kullanılmıştır. Gözlem için, hareketli bir hedefe ve Güneş'in ya da yıldızın konumunu aletin arkasındaki cetvel kullanarak ölçerken, aleti dikey olarak asacak bir halka gereklidir. Çoğu zaman usturlap, yerel ufkun üzerindeki göksel nesnelerin yüksekliklerini ölç- mek için kullanılan bir alet anlamına da gelir. Eski usturlapların incelenmesi, araştırmacılara o dönemin bilim ve astronomisini anlama olanağı sağlar. Usturlapların ayrıntılı incelenmesi; matbaa icat edilmeden önce teknik çizimlerin nasıl geliştiğini gösterir. Aynı zamanda geometrik ve analitik tekniklerin gelişimini verir. Bununla beraber bu teknikler kullanılırken oluşturulan ve kullanılan bilimsel kavramlar, kültürel etkileşimleri ortaya koyar. Ancak usturlaplar tarihsel meraktan daha fazlasıdır. Astronomi eğitiminde kullanılan en temel alettir. Usturlabı kullanmayı öğrenirken temel astronomik kavram ve sözcükler de kolayca öğrenilir. (E. Tağman, 2007, s. 23)

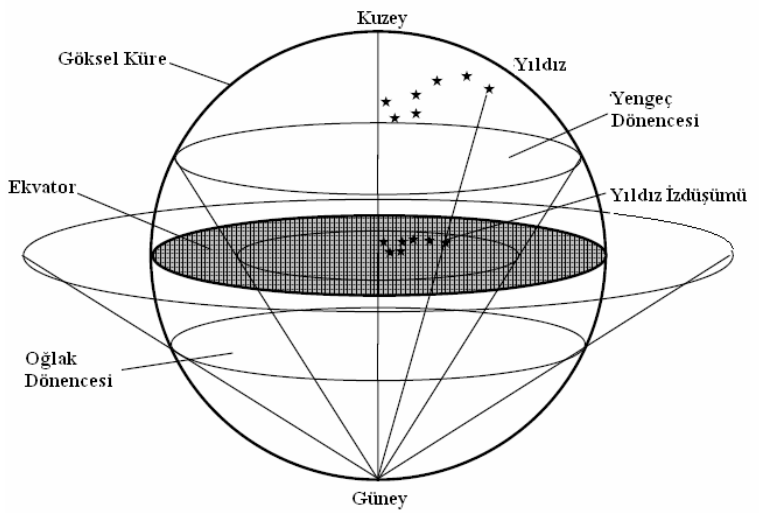

Şekil .1 Stereografik İzdüşüm

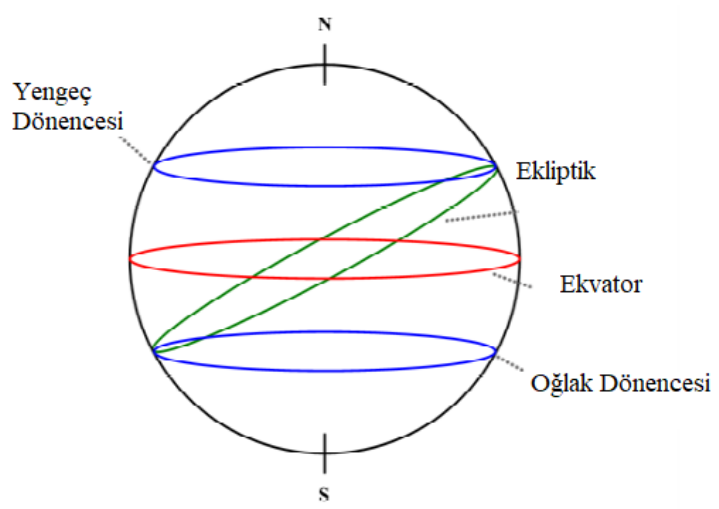

Şekil 2

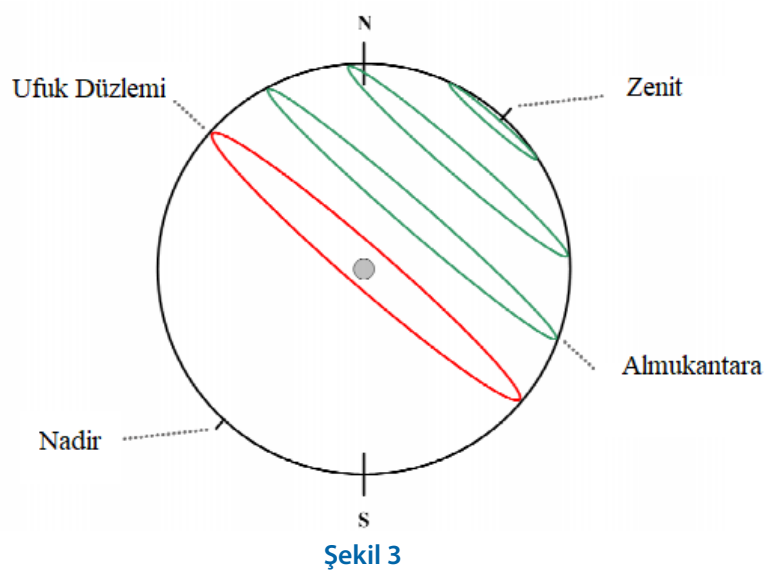

Aletin yüzünde gökyüzünün temsilinin kullanılması anlamına gelen stereografik izdüşüm yönteminden yola çıkılan usturlabın kullanımı esnek ve kolaydır. Küresel 
olan gökyüzünün, düzlemsel olana dönüștürülmesi bağlamında gökyüzünün tasavvur edilmesi oldukça zor bir uğraş gibi görünmektedir. Bununla birlikte stereografik izdüşüm eksen izdüşümlerinden yola çıkarak, nesnelerin boyutlarının uzaklıklarının değiştirilmesidir.
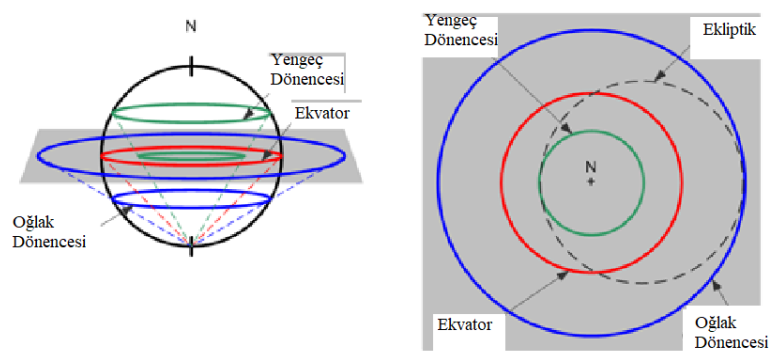

Şekil 4. İzdüşüm Yönteminin Usturlaba Uygulanması
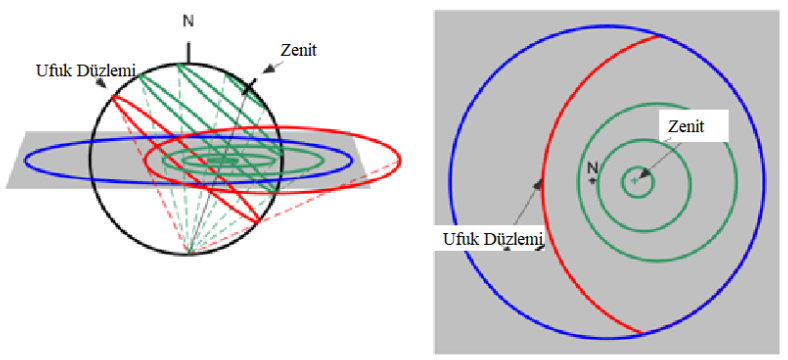

Şekil 5

Düzlemsel usturlap ve diğer ilk teleskopik astronomi aletlerinde stereografik izdüşüm yöntemi kullanılır. Bu yöntem üç boyutlu uzayın, iki boyutlu bir yüzeye yansitılmasıdır. Düzlemsel usturlap ve ilgili diğer aletler stereografik izdüşüm yöntemi olmadan düşünülemez. Yunanlılar birçok izdüşüm yöntemi denemişlerdir. Onlar bu şekildeki bir temsile "kürenin açılması" adını verirler. Stereografik izdüşümün kullanılması, yıldızların veya gezegenlerin herhangi bir zamanda, düzlem üzerinde tasarlanmasını ve buna bağlı olarak konumlarının ölçülmesini mümkün kılar. MÖ ikinci yüzyılda Hiparkos buna benzer bir çalışma yapmıştır. Teoride bütün göksel kürelerin tasarlanması mümkündür. Ancak usturlaplar kuzey yarımkürede kullanılmak için, Oğlak dönencesinin güneyindeki göksel küreleri gösterecek biçimde yapılmıştır. Bu alan Güneş'in yıllık hareketini içerir ve kuzey llıman enlemlerinden görünen tüm gökyüzünü temsil eder (E. Tağman, 2007).

Usturlabın tarihine kısaca değinmek aletin gelişimini anlamamızı kolaylaştıracaktır. Bugünkü anlamda usturlaplar MS IV. yüzyılda ortaya çıkmıştır. Aletlerde ve parçaların birleştirilmesinde stereografik izdüşümün kullanılması ilk usturlapların ortaya çıkmasında etkili olmuştur, ancak bununla ilgili herhangi bir belge mevcut değildir. Antik Yunanlardan kalma usturlapla ilgili birkaç kaynak vardır, ancak bunlar eksik ve biraz karışıtır. Usturlapla ilgili ilk kaynaklar hakkında sadece tahmin yürütebilmekteyiz. Usturlabın daha geç tarihi ile ilgili orijinal ve çeviri metinler ve bugüne kadar gelmiş olan aletlerle, usturlabın teorik temelleri, tasarımı, kul- lanılması hakkında yeterli belgeler bulunmaktadır. Bilim tarihçileri, aletlerin ve astronomi çalışmalarının incelenmesi sonucunda usturlabın tarihçesi ve gelişimi hakkında kısaca şu şekilde kronolojik bir bilgi vermektedirler:

MÖ 3. yüzyıl; Yunan matematikçi Apollonius tarafından, stereografik izdüşüm yönteminin keşfedilmesi. MÖ 2. yüzyıl; Yunan astronom Hiparkos'un usturlabın temel prensiplerini ortaya koyması. MS 2. yüzyıl; Batlamyus tarafından, matematiksel ve coğrafi temellerinin oluşturulması. MS 375; Theonl Alexandrios'un bilinen ilk usturlabın bilimsel niteliklerini vermesi. MS 771, astronom el-Fezâri'nin ilk İslamî usturlabı yapması. MS 9. yüzyıl, Fergâni'nin farklı enlemlerde işlem yapmayı olanaklı kılan 13.000 hesaplamayı yapması ve Müslüman bilim adamlarının Mekke'nin yönünün kesin olarak belirlenmesini sağlayan formülasyonu bulmaları. MS 830929, astronom Battâni'nin, Euphrates'in yıldız katalog çalışmalarını incelemesi ve usturlap üzerindeki yıldız tablolarını düzeltmesi. MS 927, astronom Nastulus'un bilinen tarihli ilk usturlabı yapması. MS 1009, astronom ibn Yunus'un 1,4 metrelik usturlap kullanarak, Güneş'in konumunun 10.000'den fazla gözlemini yapması. Onun yaptığı gözlem sonuçlarının tabloları, 19. yüzyıla kadar namaz vakitlerinin bulunmasında kullanılmıştır. MS 11. yüzyıl, el-Sakkâr'ın farklı koordinat sistemleri arasında dönüştürme yapabilmeyi sağlayan iki usturlap levhasını birleştirmesi. el-Birûni’nin göksel hareketlerin usturlaba uyarlanması ile ilgili bilgileri içeren kitap yazması.

Usturlabın temel parçaları hakkında aşağıdaki şekil bilgi verebilir

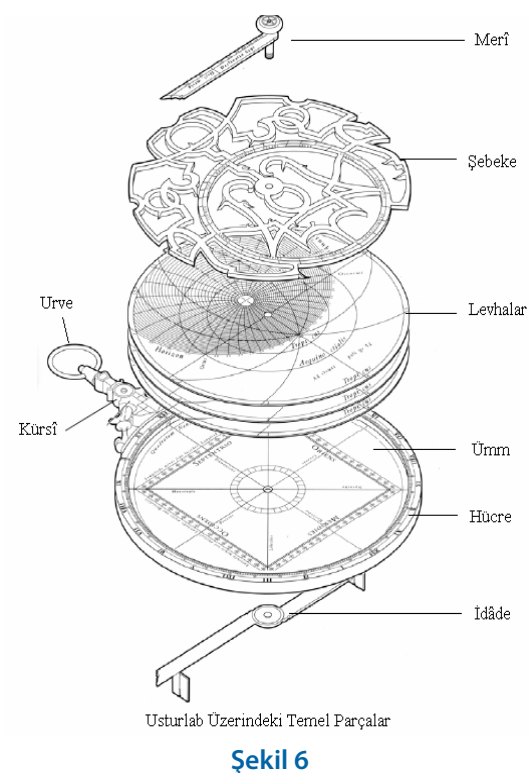

Hücre ana parçadır. Eski aletlerde genellikle $15 \mathrm{~cm}$ çapında olduğu görülmektedir. Genelde pirinçten yapılmıştır. İki parçadan oluşur; aletin arkasını tanımlayan sağlam bir levha ve aynı çapta bir halka. Bu halkaya zaman ve derece cetvelleri oyulmuştur ve arkasından levhaya tutturulmuştur. Bu halkanın kalınlığı, hücre içinde, belli bir enlemde gökyüzünün stereografik izdüşümünü gösteren 
levhaların, koyulup kullanılabileceği bir çukur olușturur. Usturlabların çoğu birçok levha içerir. Her bir levha her iki taraftan ana parçaya tutturulmuştur. Usturlabın kullanılacağı yerdeki göz erimini/ufuk düzlemini verir. Usturlablar herhangi bir enleme uygun olan levhaların takıp çıkarılabilmesine uygun olarak tasarlanmış aletlerdir.

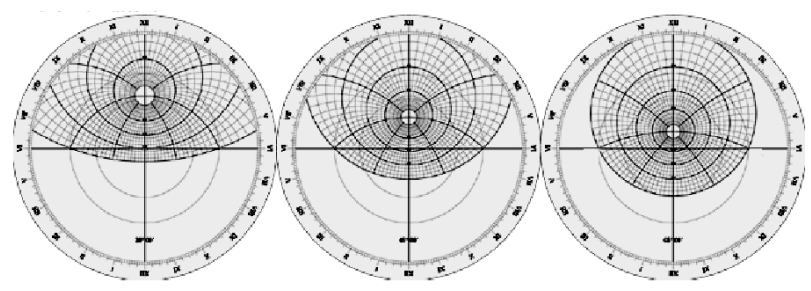

Şekil 7. $20^{\circ}, 45^{\circ}$ ve $60^{\circ}$ Enlemlerine Göre Levhalar/Diskler

Levhaların üzerinde delikli bir plaka vardır. Buna şebeke (ankebut) denir. Birçok yıldızın yerini ve ekliptiğin stereografik izdüşümünü gösterir. Birçok şebeke delik deliktir, bu şekilde kullanıcı, şebekenin altındaki levhayı görebilir. Şebeke üzerinde Güneş'in boylam cetvelinin oyulduğu ekliptik daire ve Zodyak'ı ve yıldızları gösteren ucu sivri ve kıvrımlı göstergeler vardır.

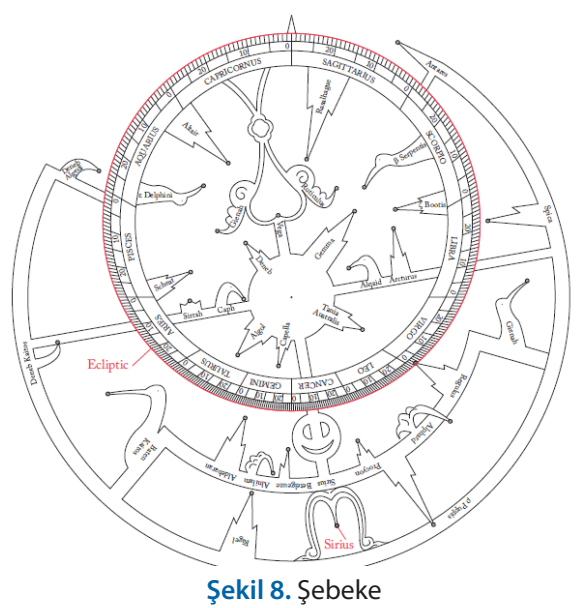

Bazı usturlaplarda ibre (merî) adı verilen, şebeke üzerinde saat ibresi ile aynı amacı yani zamanı bulmaya yarayan bir parça vardır. Bunun dışında kürsî adı verilen, usturlabın üzerinde bir parça daha vardır. Yine usturlabı asmak için kürsînin üzerinde urve adı verilen, halka seklinde bir parça daha vardır. Usturlap dik olarak kaldırıldığında, aleti parmak veya kancayla asmaya yarar. Bütün usturlapların arkasında, idâde kullanılarak gözlem yapmak için dereceli bir cetvel vardır. İdâde bağımsızdır, arka tarafın merkezinde bir eksen etrafında döner. Güneş'in ya da yıldızın yüksekliği bununla bulunur. Üzerinde bulunan cetvellerle, başka amaçlar için de kullanılır. Bunun dışında usturlap üzerinde bir yıldızı ya da Güneş'i gözlemleyerek ölçüm yapmak amacıyla "hedefe" delikleri mevcuttur. Bu deliklerden yıldız veya Güneş ya da herhangi bir nesne gözlemlenir, bu şekilde bu nesnenin yüksekliği ya da hangi işlem yapılmak isteniyorsa o gerçekleştirilir. (E. Tağman, 2007, s. 35)

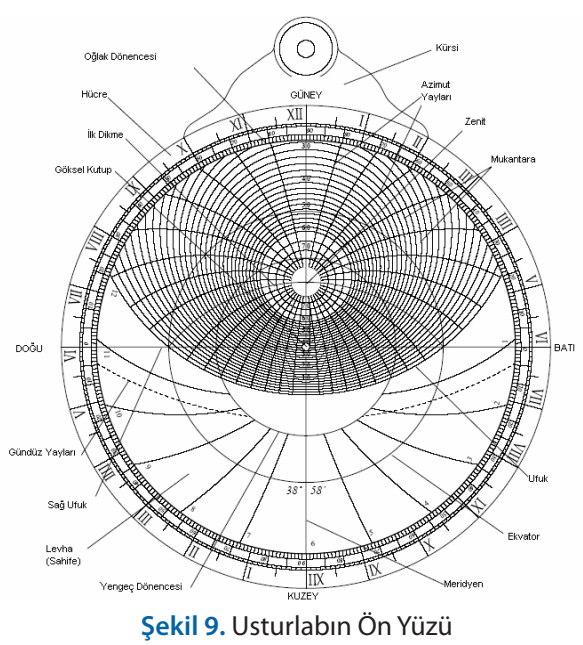

Usturlabın ön yüzü ve arka yüzü olmak üzere işlem yapılan iki bölümü vardır, her iki yüzü kullanılarak işlem yapılır, Usturlabın ön yüzü zaman ve derece tablolarını içerir. Göksel kürenin stereografik temsilidir. Usturlabın ön yüzünün temel parçası, levha adı verilen, o yerin yerel koordinat sisteminin stereografik izdüşümünü gösteren parçadır. Bu levhalar yerel ufuk ile azimut ve yükseklik dairelerinin stereografik izdüşümünü temsil eden yaylar içerir. Her bir enlem için farklı bir levhaya ihtiyaç duyulur. Her bir levha yerine uygun olarak kesilmiştir ve onu yerinde tutacak mandal ya da tutucu bir parça içerir. Levhanın dikey çapı yerel meridyeni temsil eder.

Tepe ucunun güneyi göstermesi pusulaya benzetilebilir. Ufuksal levha çapının solu doğuyu, sağı batıyı gösterir. Daha basit ifade ile doğu-batı çizgisi diye de adlandırılabilir. Levhanın merkezinde "Göksel Kuzey Kutbu'nun" izdüşümü vardır. Levhanın dış çemberi Oğlak Dönencesidir. Yengeç Dönencesi ile Ekvator'un izdüsümü ortak merkezli dairelerdir.

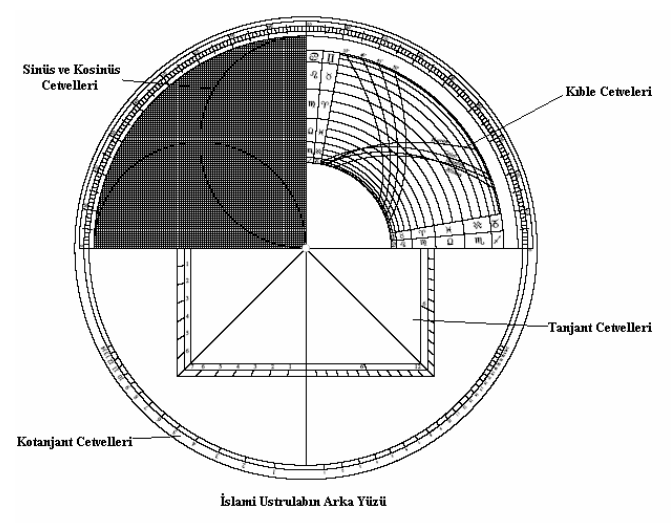

Şekil 10. Usturlabın Arka Yüzü

Usturlabın arka yüzü, Güneş'in veya bir yıldızın yüksekliğini ölçmek için cetveller içerir. Temel cetvel bütün usturlabların içermek zorunda olduğu derece cetvelleridir. Bu cetvel, Güneş'in ya da yıldızın yüksekliğini, idâdeden 
yararlanarak ölçmede kullanılır. İdâde bir merkez çevresinde döndürülebilen ve üzerinde hedefe olan bir parçadır. Küçük hedeflerden, yükseklik ölçümü yapılabilmesi için, bir yıldızın görüntüsü ya Güneş ışığı gözlemlenir.

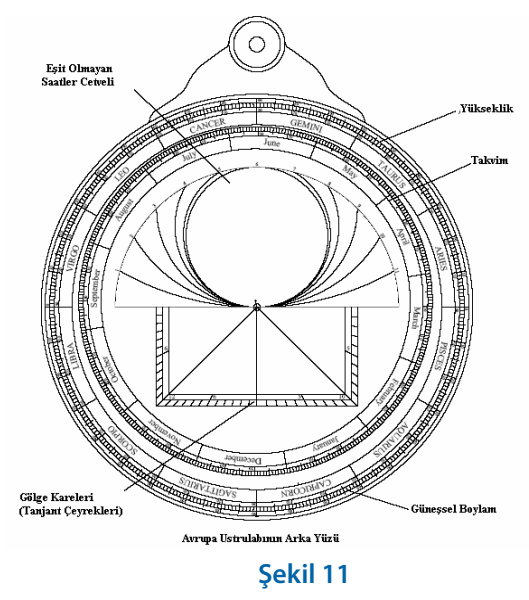

Usturlabın arkasındaki cetveller, aletin bulunduğu kültüre göre değişiklik gösterir. Ancak bütün usturlapların kenarında, yükseklik ölçümü yapılabilmesi için derece cetvelleri vardır. Usturlabın arkasındaki eşit olmayan saatler cetveli evrensel niteliktedir. Bu saatler meridyenden ve Güneş'in yüksekliğinden mevsimsel saatlerin tahmininde kullanılır. Çizimde belirtilen gölge kareleri (tanjant çeyrekleri) basit trigonometrik problemlerin çözümünde kullanılır. İslami usturlapların olağanüstü bir farklılıkları vardır. Çoğu İslami usturlap, günün beş vaktindeki namazla ilgili cetveller içerir. Bunlar astronomik olarak belirtilmiştir. En diş kenardaki derece cetvelleri Avrupa usturlapları ile aynıdır, aynı amaç için kullanılır. Üst sağ çeyrekteki yaylar, Mekke'nin yönü (istikbal-i Kıble) için kullanılır. Sol üstteki çeyrekler, Geniş alanlı trigonometrik problemlerin çözümünde sinüs ve kosinüs değerlerini bulmak için kullanılır. Gölge kareleri (tanjant çeyrekleri) Avrupa'daki usturlaplarla aynıdır. Tek fark gölge karelerinden namaz vakitlerini belirlemede de yararlanılır. Daha alt kenardaki cetvelde gölge karelerinin, daha uzayan menzillerinin kotanjant cetveli bulunur. (E. Tagman, 2007, s. 40)

Usturlapla 1500'ün üzerinde astronomik işlem gerçekleştirilebilir, bu işlemlerden en çok bilinen ve uygulananları kısaca şu şekilde sıralayabiliriz: Güneş'in yüksekliğinin bulunması, Bir yıldızın yüksekliğinin bulunması, Eşit saatlerde zamanın bulunması, Eşit olmayan saatlerde zamanın bulunması, Eşit saatlerin, eşit olmayan saatlere dönüştürülmesi, Güneş'in doğuşu ve batışının belirlenmesi, Bir yıldızın doğuş ve batışının belirlenmesi, Gün başlangıcı ve bitiminin belirlenmesi, Namaz vakitlerinin belirlenmesi, Mekke'nin yönünün bulunması, Bir yerin saatinin bilinmesi ve bu işlemden başka bir yerin yerel saatinin bulunması. Güneş'in veya bir yıldızın deklinasyonunun bulunması, Bilinen bir günde ve zamanda gölge boyunun bulunması, Bir nehir, göl veya kuyunun genişliğinin ve kuyunun derinliğinin bulunması, Zodyak'ta belirtilen bir zamandan Güneş'in konumunun bilinmesi, Güneş'in bilinen boylamına karşılık gelen, deklinasyonun bulunması, Coğrafik enlemin bulunması, Coğrafik enlemden, bir yıldızın deklinasyonunun hesaplanması, Tarih bilinmeden, Güneş'in boylamının bulunması, Bir yıldızın verilen boylam ve enleminden, deklinasyonunun ve sağ açıklığının bulunması, Güneş'in ve yıldızın yüksekliğinden zamanın bulunması, gibi işlemler usturlap kullanılarak yapılabilmektedir. (E. Tağman, 2007, s. 42) Ancak bu işlemlerin yapılabilmesi için temel astronomik kavramlar bilinmesi gerektiği unutulmamalıdır.

\section{SONUÇ}

Usturlapla ilgili işlemlerin yapılabilmesi için temel astronomik kavramlar bilinmelidir. Usturlabın kullanımı teknik bir bilgi gerektirmektedir, teorik astronomi bilgisine sahip olunmadan bu işlemler yapılabilir. Bu o dönemin astronomi anlayışına da uygun düşmektedir. Bu anlayış zamanın belirlenmesi konusunda bilgili insanlar yetiştirmekten ziyade halkın ihtiyaçlarına cevap vermektir. Çünkü hem Batı hem Doğu dünyasında dini günlerin belirlenmesi daha çok dini kurumların sorumluluğundadır. Bununla beraber İslam inancı gereği namaz ve oruç saatlerinin belirlenmesi ve halka bildirilmesi için muvakkitlik kurumu oluşturulmuştur. Bu bağlamda İslam dünyasında usturlabın yapımı, öğretimi, kullanımı ile ilgili kaynaklara (sayısal bir karşılaştırma imkânı daha doğru bir tespit yapmaya olanak sağlayacaktır) nicelik ve nitelik yönünden daha yaygın bir biçimde rastlanması muhtemeldir. Nitekim Batı'da usturlap ile ilgili temel kaynaklar da İslam dünyasındaki eserlere dayanmaktadır. Sonuç olarak gözlem yapmak ve zamanı belirlemek için başka aletlerin geliştirilmesiyle, on yedinci yüzyıldan itibaren Avrupa'da usturlabın önemi azaldı, İslam dünyasında yirminci yüzyıla kadar kullanılmaya devam etti. Günümüzde ise sadece sanatsal yönü ile öne çıkan usturlapla ilgili farklı kaynakların ortaya çıkması belki de yeni karşılaştırmaların yapılmasına da olanak sağlayacaktır.

\section{KAYNAKÇA}

Arslan, T.Y. (2016). Vakti Fethetmek. Mikat IIlmi Geleneğinde Rub'u'l Mukantarat Yapım Kılavuzu Örneği Olarak Muhammed Konevi'nin Hediyyetü'l-mülûk'u, İlmi Etüdler Derneği.

Aydüz, S. (2000). Müneccimbaşı Takvimleri ve Tarihi Kaynak Olarak Değerleri, COGiTO, Takvim Zamanın: Haritası, S. 22, Bahar, 133-149.

Aydüz, S. (2004). Osmanlı Astronomi Müesseseleri, Türkiye Araştırmaları Literatür Dergisi, Cilt 2, Sayı 4, s. 411-453.

Aydüz, S. (2008). Osmanlı Devleti'nde Müneccimbaşılık, Osmanlı Bilimi Araştırmaları: Ekmeleddin ihsanoğlu'na Armağan, Yayına Hazırlayan Feza Günergun, İstanbul, s. 159211.

Bayram, M. (1981). Anadolu 'da Te 'lif Edilen Illk Eser "Keşf-û Akabe”, İslâm Tetkikleri Enstitüsü Dergisi, Konya, s. 7-22.

Burke, P. (2004). Languages and Communities in Early Modern 
Europe. New York: Cambridge University Press.

Çevik,C. (2014). Bilim Dili Olarak Latince. https://jimithekewl. com/2014/05/28/bilim-dili-olarak-latince-mi/

Forbes, G. (1909). The Project Gutenberg E-Book of History of Astronomy: http://www.gutenberg.org/files/8172/8172-h/8172-h.htm

Gordin, M. D. (2015). Scientific Babel: How Science Was Done Before and After Global English, Chicago: The University of Chicago Press.

Grimm, M. F. (1917). Astronomical Lore of Chaucer. (Yayımlanmasş Doktora Tezi), University of Nebraska, Lincoln.

Hunger, H. \& Pingree, D. (1999). Astral Sciences in Mesopotamia, Leiden, Brill Publications.

İhsanoğlu, E. (2011). Osmanlı Bilim Literatürü Tarihi Genel İndeksi. İstanbul, İslam Tarih, Sanat ve Kültür Araştırma Merkezi (IRCICA).

İhsanoğlu, E. (2017). Osmanlı Bilim Mirası. İstanbul: Yapı Kredi Yayınları, s. 327-395.

James E. Morrison, (2007). Chaucer's Astrolabe Treatise, http:// www.chirurgeon.org/files/Chaucer.pdf

Johnson, F. R. (1944). Latin versus English: The Sixteenth-Century Debate over Scientific Terminology, Studies in Philology, Vol. 41, No. 2, s. 109-135, University of North Carolina Press, Carolina.

Kahya, E. (2003). On Besinci Yüzyılda Osmanlılarda Bilimsel Faaliyetlerin Kısa Bir Değerlendirmesi, Sosyal Bilimler Enstitüsü Dergisi, S: 1, s.11-19.

King, D. (2002). A Vetustissimus Arabic Text on the Quadrans Vetus, Journal fort he History of Astronomy 33, s. 237-255.

Neugebauer, O. (1951). The Study of Wretched Subjects. Isis 42/2 s. $111-121$.

Pearce, W. L. (2018). History of science. Encyclopedia Britannica, https://www.britannica.com/science/history-of-science.

Pines, S. (1964). The Semantic Distinction between the Terms Astronomy and Astrology according to al-Biruni, Isis, C. 55, S. 3, s. 343-349

Ronan, C. A. (2003). Bilim Tarihi (Dünya Kültürlerinde Bilimin Tarihi ve Gelişmesi). Ankara, Çev: E. İhsanoğlu, F. Günergun, Tübitak.

Sarton G. \& Siegel, F. (1950). Seventy-Sixth Critical Bibliography of the History and Philosophy of Science and of the History of Civilization, Isis 41/3-4, 328-424.

Sayılı, A. (1985). Ortaçağ Bilim ve Tefekküründe Türklerin Yeri, Atatürk Kültür, Dil ve Tarih Yüksek Kurumu, Ankara: Atatürk Kültür Merkezi, Türk Kültüründen Görüntüler Dizisi, Sayı: I.

Sezgin, F. (2008). İslam ^da Bilim ve Teknik, C. II, Astronomi, İstanbul: TÜBA, IBB Kültür AŞ. Yayınları.

Skeat, W. W. (1879). A Treatise on the Astrolabe, Early English Text Society, London.

Swerdlow, N. M. (1999). Ancient Astronomy and Celestial Divination. Baltimore: Dibner Institute Studies in the History of Science and Technology, MIT Press.

Şen, A. T. (2016). Astrology In The Service Of The Empire: Knowledge, Prognostication, And Politics At The Ottoman Court, 1450s-1550s, (Yayımlanmamış Doktora Tezi), The Univer- sity Of Chicago, Chicago.

Tağman, S. E. (2007), Mustafa bin Ali el-Muvakkit'in Usturlab Risalesi, (Yayımlanmamış Yüksek Lisans Tezi), Ankara Üniversitesi, Sosyal Bilimler Enstitüsü, Ankara.

Unat, Y. (1999). Osmanlı Astronomisine Genel Bir Bakış, Osmanlı, Cilt 8, Yeni Türkiye Yayınları, s. 411 - 420.

Usturlap ile ilgili daha ayrıntılı bilgi edinmek ve kendi usturlabını yapmak isteyenler aşağıdaki adresi ziyaret edebilir: https://www.shadowspro.com/en/index.html 


\section{Ek:1 Usturlapla Gün Doğum Zamanının Belirlenmesi}

- Aşağıdaki örnek $52^{\circ}$ enleme (Cambridge-İngiltere) göre, Dominic Ford and Katie Birkwood tarafından, Geoffrey Chaucer'in 1391 tarihli “Treatise on the Astrolabe" başlıklı çalışmasının Eisner tarafından yapılan replikasının basitleştirilmiş ve günümüze uyarlanmış halidir. Ticari niyetle kullanılmaması şartıyla yazarların izni alınmıştır.

- Ölçüm yapılacak günün tarihi belirlenir.

- Usturlabın arka yüzünde idade yardımıyla $10 \mathrm{Ni}$ san'in, Koç Burcu'nun 20. gününe denk geldiği görülüyor.

- Usturlabın ön yüzünde, şebeke üzerinde ibre Koç burcunun 20'sine getirilir. Şebeke ile ibre birlikte doğu ufuk çizgisine (sol tarafta) gelene kadar birlikte çevrilir. Doğu ufku ile kesiştiği nokta Güneş'in doğuş saatini belirler. 
Ana Parça : Arka

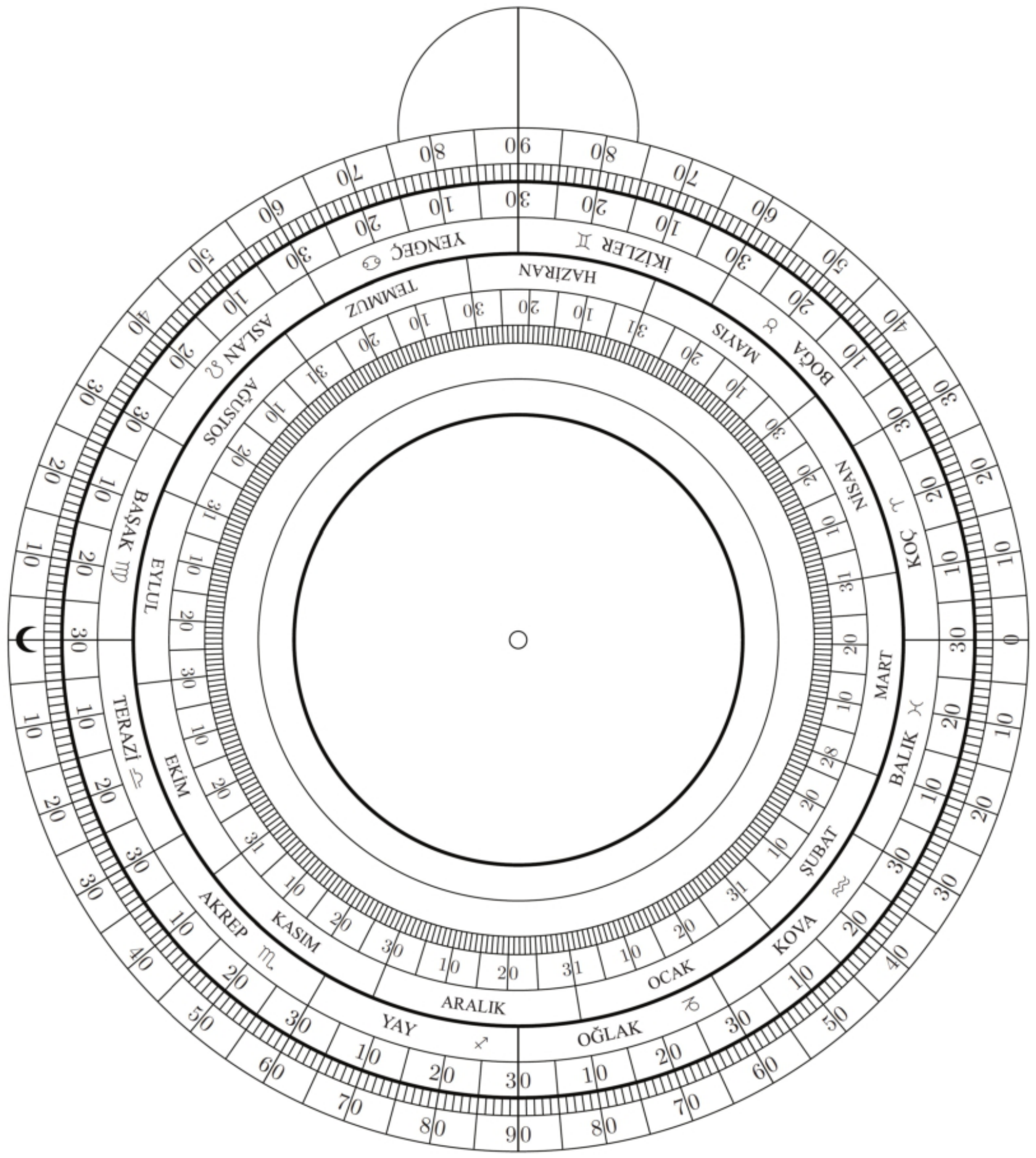


Ana Parça : Ön

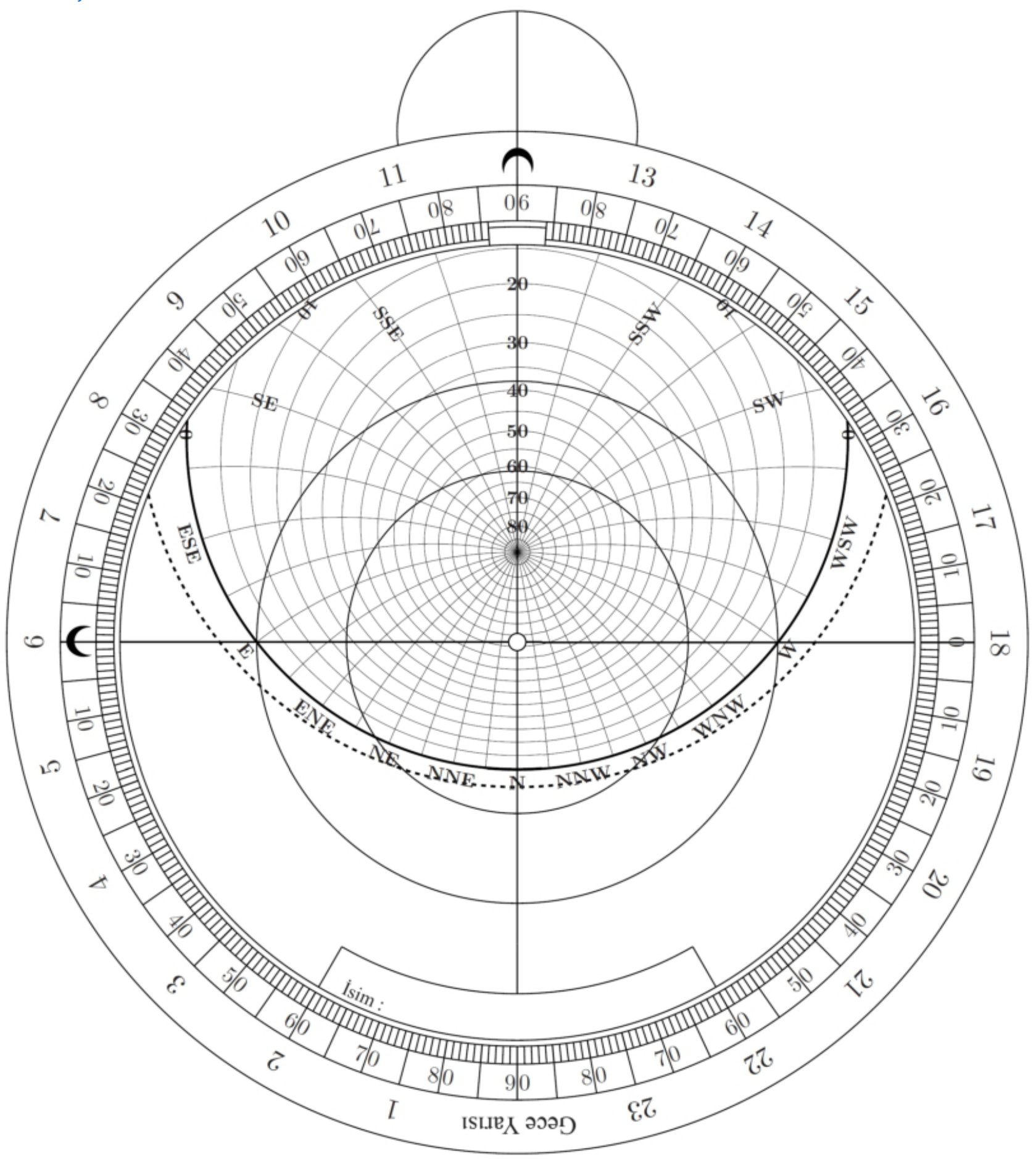


Şebeke

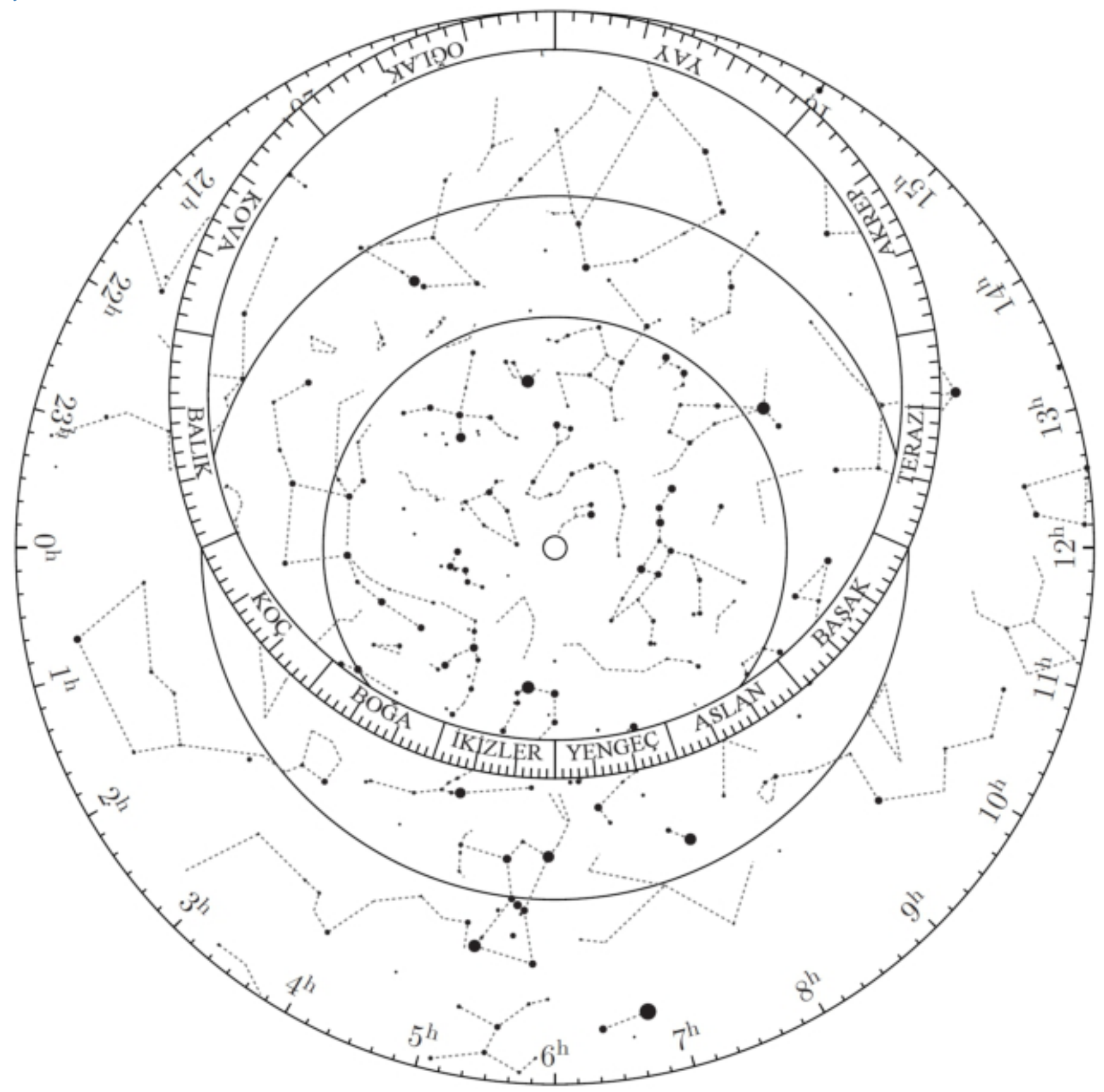




\section{İbre ve İdade}

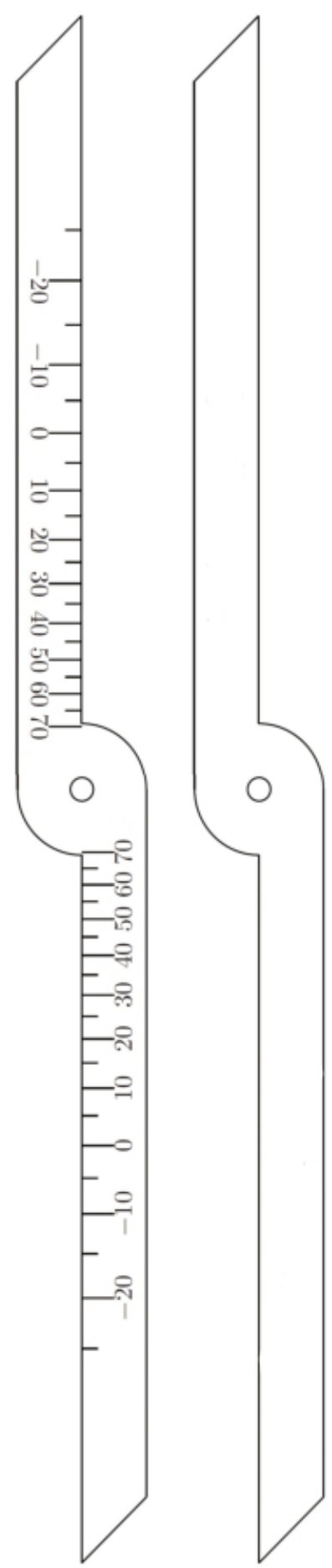

